\title{
Sugar-sweetened beverages consumption and BMI in Mexican adolescents. Mexican National Health and Nutrition Survey 2006
}

\author{
Alejandra Jiménez-Aguilar, MSc,, ${ }^{(1)}$ Mario Flores, MD, MSc, ${ }^{(1)}$ Teresa Shamah-Levy, MSc.(I)
}

\author{
Jiménez-Aguilar A, Flores M, Shamah-Levy T. \\ Sugar-sweetened beverages consumption \\ and BMI in Mexican adolescents. \\ Mexican National Health and Nutrition Survey 2006. \\ Salud Publica Mex 2009;5 I suppl 4:S604-S6I 2.
}

\begin{abstract}
Objective. To evaluate the association between the consumption of sugar-sweetened beverages (SSBs) and body mass index (BMI) in Mexican adolescents. Material and Methods. We analyzed the data of 10689 adolescents (ages 10 to 19 years old) who participated in the Mexican National Health and Nutrition Survey 2006 (ENSANUT 2006). Consumption of SSBs (i.e. sodas, fruit beverages and sugar beverages) was evaluated by means of a semi-quantitative food frequency questionnaire. BMI was calculated $\left(\mathrm{kg} / \mathrm{m}^{2}\right)$. Results. Mean age was I $3.8 \pm 2.7$ years. Fifty percent were females. Mean BMI was $21.7 \pm 4.5$. Thirty percent of adolescents were overweight or obese. Ninety percent of adolescents consumed at least one SSB during the 7 days before the interview. The median consumption of SSBs was 0.89 portion per day. Multiplelinear regression analysis showed that for each portion of sodas consumed, a 0.17-point increase in BMI was observed in boys after adjusting for confounders (95\% Cl; 0.02-0.32, $p$ 0.03). Positive interactions of SSB consumption with age and time watching TV were observed in boys. Conclusions. Consumption of sodas was positively associated with BMI in Mexican boys.
\end{abstract}

Key words: beverages; body mass index; overweight; obesity; adolescents; Mexico
Jiménez-Aguilar A, Flores M, Shamah-Levy T.

Consumo de bebidas azucaradas

y su relación con el IMC en adolescentes mexicanos.

Encuesta Nacional de Salud y Nutrición 2006.

Salud Publica Mex 2009;5I supl 4:S604-S6I 2.

\section{Resumen}

Objetivo. Examinar la asociación entre el consumo de bebidas refrescantes azucaradas (BRA) y el índice de masa corporal (IMC) en adolescentes mexicanos. Material y métodos. Se analizaron datos de 10689 adolescentes ( 10 a 19 años de edad) de la Encuesta Nacional de Salud y Nutrición 2006 (ENSANUT 2006). El consumo de bebidas refrescantes azucaradas (BRA: refrescos, bebidas de fruta y bebidas endulzadas) se evaluó con un cuestionario semicuantitativo de frecuencia de consumo de alimentos. Se calculó el índice de masa corporal $\left(\mathrm{kg} / \mathrm{m}^{2}\right)$. Resultados. La media de edad fue de $13.8 \pm 2.7$ años. El $50.4 \%$ fueron mujeres. La media de IMC fue de $21.7 \pm 4.5$. Un $30 \%$ de los adolescentes presentó sobrepeso u obesidad. El $90 \%$ de los adolescentes consumieron al menos una BRA en los 7 días previos a la encuesta, con una mediana de 0.89 porciones/día. El análisis de regresión lineal mostró que por cada porción consumida de refrescos, el IMC en los adolescentes varones aumentó 0.17 unidades, después de ajustar por variables confusoras (IC 95\%: 0.02, 0.32, $p=0.03$. Se observaron interacciones entre el consumo de BRA con la edad y el tiempo viendo televisión en los varones adolescentes. Conclusiones. El consumo de refrescos se asoció positivamente con el IMC en varones adolescentes mexicanos.

Palabras clave: bebidas; índice de masa corporal; sobrepeso; obesidad; adolescentes; México

(I) Centro de Investigación en Nutrición y Salud, Instituto Nacional de Salud Pública. Cuernavaca, Morelos, México.

Received on: April II, 2008 • Accepted on: February 25, 2009

Address reprint requests to: Dr. Mario Flores. Instituto Nacional de Salud Pública. Av. Universidad 655

col. Santa María Ahuacatitlán. 62100 Cuernavaca, Morelos, México.

E-mail:mflores@correo.insp.mx 
$\mathrm{T}^{\mathrm{h}}$ he prevalence of overweight and obesity have dramatically increased in Mexico. ${ }^{1}$ The most recent Mexican National Health and Nutrition Survey (ENSANUT 2006) found that one out of three adolescents is overweight or obese. ${ }^{2}$ At the same time an increase in consumption of sugar-sweetened beverages (SSBs) -such as sodas, fruit beverages and sweet-flavored drinks- has been observed. Mexico is the second largest consumer of soft drinks, after the US. ${ }^{3}$ According to data from National Income-Expenditure Surveys (NIES) household expenditure on soft drinks has risen by $37.2 \%$ between 1986 and $1998 .{ }^{1}$ At present, beverages contribute a fifth of all calories consumed by Mexicans. Because of this increase, recent Mexican guidelines suggest that energy from beverages must not exceed $10 \%$ of the recommendations of total energy. ${ }^{4}$

Recent evidence has shown that a high consumption of SSBs was associated with body weight gain and obesity in different populations..$^{5}$ In Mexico, there is scarce information about this problem.

The objective of the present study is to examine the association between consumption of SSBs and body mass index (BMI) in Mexican adolescents using data from the ENSANUT 2006.

\section{Material and Methods}

This is a cross-sectional, observational study based on data of adolescents who participated in the 2006 Mexican National Health and Nutrition Survey (ENSANUT 2006). The methods for this survey have been described in detail elsewhere. ${ }^{2}$

Briefly, the ENSANUT 2006 was a probabilistic survey with a complex, stratified sampling design, carried out between October 2005 and May 2006. The ENSANUT 2006 is representative of four regions (north, center, south and Mexico City) ${ }^{*}$ and of rural $(<2500$ population) and urban ( $\geq 2500$ population) areas in the Mexican Republic. It obtained information from 48304 households. ${ }^{\ddagger}$

\footnotetext{
* The regions were established according to the definition by INEGI (National Institute of Statistics, Geography and Informatics): north (Baja California, Baja California Sur, Coahuila, Chihuahua, Durango, Nuevo Leon, Sonora and Tamaulipas), center (Aguascalientes, Colima, Guanajuato, Jalisco, Mexico (excluding urbanized municipalities and localities adjacent to Mexico City), Michoacan, Morelos, Nayarit, Queretaro, San Luis Potosi, Sinaloa, and Zacatecas), Mexico City (including the Federal District and urbanized municipalities in the State of Mexico), and south (Campeche, Chiapas, Guerrero, Hidalgo, Oaxaca, Puebla, Quintana Roo, Tabasco, Tlaxcala, Veracruz and Yucatan).

₹ A household unit was defined as all persons who usually sleep in the same house and benefit from a common income, whether or not they are connected by kinship.
}

For determining sample size it was considered that the minimum interest prevalence should have an accuracy of $8.1 \%$. It was also considered that state estimators obtained through the survey should have a $25 \%$ maximum relative error, a 95\% confidence interval, a $20 \%$ non response rate, and a design effect of 1.7, determining a sample size of at least 1476 households by state. A subsample corresponding to a third of the whole sample was selected for dietary information. ${ }^{2}$

The study sample was limited to adolescents (boys and girls 10 to 19 years old) who had dietary data. Prior to the interview, informed consent was obtained from the family head and from the adolescent. Protocol was reviewed and approved by the Ethics, Bio-safety and Research Committees at the National Institute of Public Health (INSP).

Dietary information. Trained personnel conducted an adapted version of the food-frequency semi-quantitative questionnaire (FFSQ), for its application in digital format; found in the Procedure Handbook for Nutrition Projects, published by the INSP. ${ }^{6}$ The questionnaire included 101 food and beverage items classified into 14 groups. Data were entered into HP Compaq nx 6120 and Dell Latitude D510 laptop computers. Personnel from the INSP developed and validated the electronic questionnaires for input of data into the Fox Pro program version 7.

Non beverages energy. Dietitians converted the reported consumptions into grams or $\mathrm{ml}$ of food and beverages items. Energy from sources other than SSBs was then calculated using a comprehensive database compiled from diverse sources. * For data cleanup, observations with an energy intake less than $500 \mathrm{kcal}$ or more than 7000 kcal were eliminated. ${ }^{7}$

Consumption of sugar-sweetened beverages. The standard portion of beverages was a $240 \mathrm{ml}$ glass. The FFSQ collected information about the consumption of sodas, fruit drinks, sugar beverages and diet beverages. Participants were asked for the numbers of days (never, one, two to four, five to six, and seven days), times a day (one, two to three, four to five, and six times per day), and total of glasses consumed for each beverage during a seven-day period before the interview. We obtained the total consumption of each beverage from the number of servings per day. The consumption of diet beverages was categorized as low or high intake with respect to the median of its distribution.

\footnotetext{
* Safdie M, Barquera S, Porcayo M, Rodríguez S, Ramírez C, Rivera $\mathrm{J}$, et al. Bases de datos del valor nutritivo de los alimentos. Compilación del Instituto Nacional de Salud Pública, 2004. (Unpublished document).
} 
Body mass index. Standardized interviewers ${ }^{8,9}$ took measurements of weight with a portable electronic scale (Tanita) with a precision of $100 \mathrm{~g}$. Height was obtained with a Dynatop stadiometer, with a capacity of 2 meters and an accuracy of $1 \mathrm{~mm}$.

Body mass index was calculated as the weight in kilograms divided by the height in meters squared. BMI data were considered valid when they were between 10 and 58 units. ${ }^{2}$ The classification of overweight and obesity was done in accordance with age and sex-specific BMI cut points recommended by the International Obesity Task Force (IOTF). ${ }^{2,10}$ The $15^{\text {th }}$ percentile of NCHS' weightfor-age z-scores was used to identify individuals with low weight. ${ }^{11}$

Socieconomic status. An indicator of socioeconomic status (SES) was constructed using a principal components analysis. ${ }^{12,13}$ It included variables related to housing conditions (such as flooring and roofing materials), home appliances (including refrigerators, stoves, washing machines, TV sets, radios, videoplayers, telephones, and computers) and number of rooms (other than bathrooms, kitchens and corridors). The first component accounted for $46 \%$ of the total variance. The standardized factor was divided into tertiles.

$T V$ viewing. To estimate TV viewing time, we used the Mexican students questionnaire (CAINM) developed following the format of the Youth Activity Questionnaire (YAQ). The CAINM was previously validated among adolescents in Mexico City and the results show that the questionnaire was valid (adjusted $\mathrm{r}=0.51$, disattenuated $\mathrm{r}=0.69, p<0.05)$ and that it had an acceptable reproducibility $(r=0.53, p<0.05)$ to estimate TV-viewing time. ${ }^{14}$ The questionnaire was administered directly to the adolescents. It asked about the number of hours a week they spent watching TV, including weekends. The total number of hours per week spent watching TV was estimated. This variable was divided into categories in accordance with criteria by the American Academy of Pediatrics. ${ }^{15}$

Sex and age. Sex and age was obtained by the survey team.

Presence of menarche. Presence of menarche was obtained by interviews and used as an indicator of sexual maturation in girls. ${ }^{16}$

Data Analysis. Descriptive statistics (medians, 25th and 75th percentiles) of servings per day of SSBs were obtained. Median intakes of SSBs across biological and socioeconomic categories were compared. Differences between categories were obtained by median regressions.

To assess the relationship between consumption of SSBs and BMI, linear regression models were developed.
After examination of multi-collinearity, beverages as servings consumed per day were included simultaneously as independent variables (sodas, fruit drinks and sugar beverages). The variable SSBs as a group was tested in another model.

We sequentially adjusted for sets of variables that might confound the association between SSBs and BMI: non-beverage energy, diet drinks, region (urban or rural), age, SES, and time watching TV. Models were stratified by sex, and for female adolescents presence of menarche was included.

Two-way interaction terms were tested in the linear regression models for consumption of SSBs and age, and for TV-viewing and menarche.

Sampling weights (expansion factors) were calculated as the inverse of the selection probability for each individual, accordingly to the sampling scheme used. ${ }^{2}$ All calculations were weighted by expansion factors and adjusted for sampling (clustering) effects using the SVY STATA 9.0 module (Stata Corporation, TX, USA)* for complex surveys. A statistically significant level of 0.05 was used.

\section{Results}

A total of 10884 observations met the inclusion criteria, but 195 were eliminated due to implausible energy intake values. Thus, we analyzed data from 10689 individuals, representative of up to 10 million adolescents in Mexico.

The comparison between subjects included and excluded from analysis showed no significant differences with respect to age, sex or BMI $(p>0.05)$.

Fifty percent of the subjects were female adolescents. The mean age was $13.8 \pm 2.7$ years. More than $30 \%$ of the male adolescents were in the group of 13 to 15 years, and nearly $30 \%$ of the females were in the oldest age group (16 to 19 years). Mean BMI was $21.4 \pm$ 4.4. On average, female adolescents had a higher BMI and a higher prevalence of overweight in relation to males $(p<0.05)$. The greater proportion of adolescents had a low SES (49.9\%). Adolescents were concentrated in the center $(39.8 \%)$ and southern $(40.6 \%)$ regions of the country. The greater proportion of adolescents lived in urban areas $(57.5 \%)$. The average time watching TV was $7.5 \pm 5.5 \mathrm{~h} / \mathrm{w}$. Fifty-two percent of adolescents watched TV less than seven hours a week. A higher proportion of female adolescents watched TV for more than 21 hours a

\footnotetext{
* Stata Corp. Intercooled Stata 9.2 College Station Texas, USA, 2006.
} 
Table I

\section{Characteristics of adolescents. Mexico, ENSANUT 2006}

\begin{tabular}{lccc} 
Characteristic & National & $\begin{array}{c}\text { Males } \\
\%\end{array}$ & $\begin{array}{c}\text { Females } \\
\%\end{array}$ \\
$\begin{array}{l}\text { Population size* } \\
\text { Age, (years) } \\
10 \text { to } 12\end{array}$ & 100.0 & 49.6 & 50.4 \\
\hline 13 to $15 \$$ & 36,3 & 36,0 & 36,5 \\
\hline 16 to $19 \$$ & 35,1 & 37.3 & 33.0 \\
\hline
\end{tabular}

\begin{tabular}{llll}
$\begin{array}{l}\text { Menarche } \\
\text { Yes }\end{array}$ & - & - & 70,8 \\
\hline No & - & - & 29,2
\end{tabular}

Body weight

\begin{tabular}{lrrr} 
Normal & 64,5 & 64,3 & 64,6 \\
\hline Underweight $^{\ddagger}$ & 7,2 & 9.0 & 5.5 \\
\hline Overweight $^{\S}$ & 20,4 & 18.9 & 21.9 \\
\hline Obesity & 7,9 & 7,8 & 8,0
\end{tabular}

Socioeconomic status

\begin{tabular}{llll} 
Low & 49,9 & 49,7 & 50,2 \\
\hline Medium & 30,7 & 30,2 & 31,3 \\
\hline High & 19,3 & 20,1 & 18,5
\end{tabular}

Region

\begin{tabular}{lrrr} 
North & 12,8 & 13,0 & 12,5 \\
\hline Center & 39,8 & 39,8 & 39,9 \\
\hline Mexico City & 6,8 & 6,9 & 6,6 \\
\hline South & 40,6 & 40,3 & 41,0
\end{tabular}

Area

\begin{tabular}{cccc} 
Urban & 57,5 & 57,3 & 57,7 \\
\hline Rural & 42,5 & 42,7 & 42,3
\end{tabular}

Time watching TV, hrs/wk

\begin{tabular}{lrrr}
$<7$ & 52,0 & 52,5 & 51,5 \\
\hline$\geq 7$ to $<14$ & 33,6 & $34, I$ & 33,1 \\
\hline$\geq \mid 4$ to $2 \mid$ & 12,2 & 11,7 & 12,7 \\
\hline$>\left.2\right|^{\S}$ & 2,2 & 1.7 & 2.7
\end{tabular}

Mean (SD)

\begin{tabular}{lrrr} 
Age, years & $13.8(2.7)$ & $13.8(2.6)$ & $13.9(2.7)$ \\
\hline $\mathrm{BMI}^{\ddagger}$ & $2 \mathrm{I} .4(4.4)$ & $2 \mathrm{I} . \mathrm{I}(4.3)$ & $2 \mathrm{I} .7(4.5)$ \\
\hline Menarche, years & - & - & $12 . \mathrm{I}(\mathrm{I} .2)$ \\
\hline Time watching TV, h/w & $7.5(5.5)$ & $7.4(5.4)$ & $7.7(5.6)$
\end{tabular}

* National sample size:10 689 Expansion factor: 10029 247; Male sample size: 5298 Expansion factor: 4 97| I24 Female sample size: 5 39| Expansion factor: 5058 I23

¥ Significant difference between males and females $(p<0.00$ I adjusted in a lineal regression model or in a logistic regression model)

$\S$ Significant difference between males and females $(p<0.05$ adjusted in a lineal regression model or in a logistic regression model) week as compared to males $(p<0.05)$.The average age at menarche was $12.1 \pm 1.2$ years and $70.8 \%$ of the females already had it (Table I).

During the seven days prior to the survey, $77.2 \%$ of the adolescents consumed sodas, $39.7 \%$ consumed

Table II

Number OF SERVINGS PER DAY OF SUGAR-SWEETENED BEVERAGES, * BY DIFFERENT CHARACTERISTICS of ADOlescents. MeXico, ENSANUT 2006

\begin{tabular}{lccc} 
& & \multicolumn{2}{c}{ Percentile } \\
\cline { 3 - 4 } Characteristic & Median & 25 & 75 \\
National & 0.89 & 0.43 & 1.96 \\
Sex & & & \\
Males & & & \\
\hline Females & $1.00^{\ddagger}$ & 0.43 & 2.07 \\
$\begin{array}{l}\text { Age, (years) } \\
\text { I0 to } 12\end{array}$ & $0.86^{\S}$ & 0.36 & 1.71 \\
\hline 13 to 15 & & & \\
\hline 16 to 19 & $0.79 \ddagger$ & 0.29 & 1.50 \\
\hline & $1.00^{\S}$ & 0.43 & 2.00 \\
\hline & $1.00 \$$ & 0.43 & 2.08
\end{tabular}

Menarche

\begin{tabular}{llll} 
Yes & $0.89^{\ddagger}$ & 0.43 & 1.88 \\
\hline No & $0.68^{\S}$ & 0.29 & 1.43
\end{tabular}

Body weight

\begin{tabular}{llll} 
Normal & $0.86^{\ddagger}$ & 0.40 & 1.93 \\
\hline Underweight & $0.86^{\ddagger}$ & 0.29 & 1.71 \\
\hline Overweight & $1.00^{\S}$ & 0.43 & 2.00 \\
\hline Obesity & $0.89^{\#}$ & 0.43 & 2.00
\end{tabular}

Socioeconomic status

\begin{tabular}{llll} 
Low & $0.64^{\ddagger}$ & 0.17 & 1.43 \\
\hline Medium & $1.02^{\S}$ & 0.43 & 2.14 \\
\hline High & $1.21^{\#}$ & 0.51 & 2.50
\end{tabular}

Region

\begin{tabular}{llll} 
North & $1.21^{\ddagger}$ & 0.57 & 2.50 \\
\hline Center & $1.00^{\S}$ & 0.43 & 2.07 \\
\hline Mexico City & $1.00^{\S}$ & 0.43 & 2.00 \\
\hline South & $0.67^{\#}$ & 0.14 & 1.45 \\
Area & & & \\
Urban & & & \\
\hline Rural & $1.07^{\ddagger}$ & 0.43 & 2.14 \\
\hline
\end{tabular}

Time watching TV, hrs/wk

\begin{tabular}{llll}
$<7$ & $0.79^{\ddagger}$ & 0.29 & 1.57 \\
\hline$\geq 7$ to $<14$ & $1.00^{\S}$ & 0.43 & 2.08 \\
\hline$\geq 14$ to 21 & $1.07^{\#}$ & 0.43 & 2.33 \\
\hline$>21$ & $1.00^{\S}$ & 0.43 & 2.14
\end{tabular}

* Servings consumed 7 days prior to the survey

Categories with a common superscript $(\$, \delta, \#)$ are not statistically distinguishable from one category to another at the $p=0.05$ level. (Adjusted in a lineal regression for medians) 
fruit beverages and $27.7 \%$ consumed sugar beverages. Ninety percent consumed one or more SSBs. On average, a somewhat higher percentage of male adolescents consumed sodas (79\%) compared to females $(75.5 \%)(p<$ $0.01)$. Moreover, approximately $91 \%$ of males and $89 \%$ of females $(p<0.05)$ consumed one or more SSBs (data not shown).

At the national level, the daily median consumption of SSBs was 0.89 (percentile 25: 0.43, p75: 1.96). Median SSB consumption was higher for male adolescents than for females $(p<0.001)$. Median SSB consumption was higher among older adolescents (13 to 19 years) compared to the youngest adolescents (10 to 12 years). In general, overweight adolescents consumed more SSBs compared to adolescents who had a normal weight. The consumption of SSBs was positively associated with SES. A higher consumption of SSBs was observed in the northern region and in urban areas $(p<0.05)$. Adolescents who already had menarche consumed, on average, more SSBs than those who had not yet had it $(p<0.05)$. Adolescents who watched less than $7 \mathrm{hrs}$ of TV per week consumed less SSBs $(p<0.05)$ (Table II).

For male adolescents, the unadjusted analysis showed that consumption of sodas was positively associated with BMI. For each serving of soda consumed, BMI increased 0.54 units (95\% CI: 0.39-0.70, $p<0.001$ ), whereas consumption of fruit drinks and sugar beverages were not significantly associated with BMI. It was noted that before adjusting for non-beverage energy the coefficient related to the consumption of soft drinks decreased ( $\beta=0.16,95 \%$ CI: 0.01-0.31, $p=0.04$ ), while after adjustment for non-beverage energy the coefficient increased slightly ( $\beta=0.17,95 \%$ CI: $0.02-0.32, p=0.03$ ). None showed significant associations between consumption of fruit drinks and sugar beverages with BMI before or after adjusting for non-beverage energy. After adjusting for non-beverage energy, the consumption of all SSBs were not significantly associated with BMI in male adolescents $(\beta=0.06,95 \%$ CI: $-0.04-0.17, p=0.25)$ (Table III).

In female adolescents, the unadjusted model showed that for every serving of soda consumed, BMI increased 0.19 units (95\% CI: 0.03-0.35, $p=0.03$ ). For fruit drinks and sugar beverages, no significant associations were observed. The adjusted analysis showed that before and after adjusting for non beverages energy, no drink studied, including the set of SSBs was significantly associated with BMI in females (Table III).

Figure 1 presents the adjusted mean BMI for male adolescents derived from the regression models that included interaction terms between the consumption of SSBs and age, and between the consumption of SSBs and TV-viewing time. In panel A, it is observed that in each age group, males with a higher consumption of SSBs had a higher BMI compared to those with a lower consumption of SSBs $(p<0.05)$.

Table III

RELATIONSHIP BETWEEN NUMBERS OF SERVINGS CONSUMED PER DAY OF THE STUDIED BEVERAGES AND the body mass INDEX OF the ADOLESCEnTs. MeXico, ENSANUT 2006*

\begin{tabular}{|c|c|c|c|c|c|c|c|c|c|c|c|c|}
\hline \multirow{3}{*}{$\begin{array}{l}\text { Beverages } \\
\text { Males }\end{array}$} & \multicolumn{4}{|c|}{ Unadjusted } & \multicolumn{4}{|c|}{ Before non beverage energy adjustment } & \multicolumn{4}{|c|}{ After non beverage energy adjustment } \\
\hline & \multirow[t]{2}{*}{$\beta(B M I)$} & \multicolumn{2}{|c|}{$95 \% \mathrm{Cl}$} & \multirow[t]{2}{*}{$p$} & \multirow[t]{2}{*}{$\beta(B M I)$} & \multicolumn{2}{|c|}{$95 \% \mathrm{Cl}$} & \multirow[t]{2}{*}{$p$} & \multirow[t]{2}{*}{$\beta(B M I)$} & \multicolumn{2}{|c|}{$95 \% \mathrm{Cl}$} & \multirow[t]{2}{*}{$p$} \\
\hline & & & & & & & & & & & & \\
\hline Sodas & 0.54 & 0.39 & 0.70 & 0.00 & 0.16 & 0.01 & 0.31 & 0.04 & 0.17 & 0.02 & 0.32 & 0.03 \\
\hline Fruit drinks & -0.01 & -0.18 & 0.17 & 0.95 & -0.09 & -0.25 & 0.08 & 0.29 & -0.08 & -0.24 & 0.09 & 0.35 \\
\hline Sugar beverages & 0.11 & -0.06 & 0.29 & 0.21 & 0.02 & -0.19 & 0.23 & 0.85 & 0.03 & -0.19 & 0.24 & 0.81 \\
\hline Sugar-sweetened beverages ${ }^{\ddagger}$ & 0.29 & 0.18 & 0.39 & 0.00 & 0.05 & -0.05 & 0.16 & 0.32 & 0.06 & -0.04 & 0.17 & 0.25 \\
\hline \multicolumn{13}{|l|}{ Females } \\
\hline Sodas & 0.19 & 0.03 & 0.35 & 0.03 & -0.11 & -0.27 & 0.06 & 0.22 & -0.07 & -0.23 & 0.10 & 0.44 \\
\hline Fruit drinks & -0.03 & -0.20 & 0.15 & 0.76 & -0.14 & -0.30 & 0.03 & 0.10 & -0.09 & -0.25 & 0.07 & 0.28 \\
\hline Sugar beverages & 0.02 & -0.23 & 0.27 & 0.88 & -0.08 & -0.31 & 0.15 & 0.51 & -0.04 & -0.27 & 0.20 & 0.77 \\
\hline Sugar-sweetened beverages ${ }^{\ddagger}$ & 0.09 & -0.02 & 0.20 & 0.11 & -0.11 & -0.22 & 0.00 & 0.05 & -0.07 & -0.18 & 0.04 & 0.23 \\
\hline
\end{tabular}




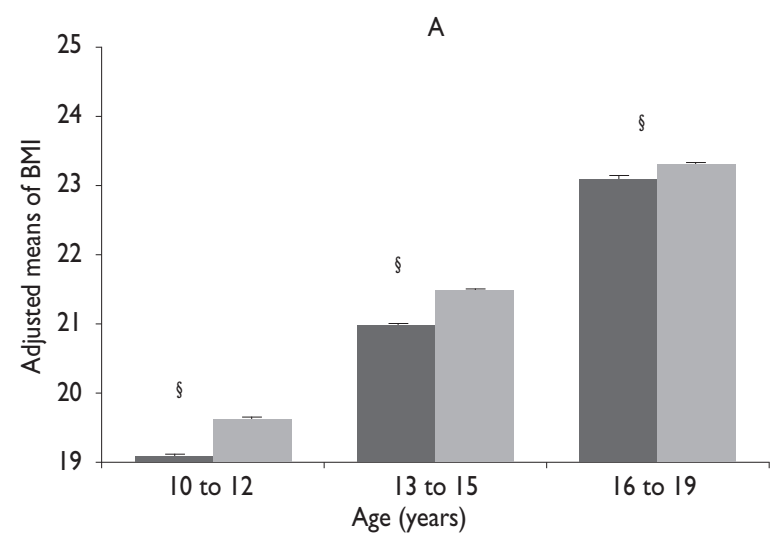

Servings per day: Low intake*

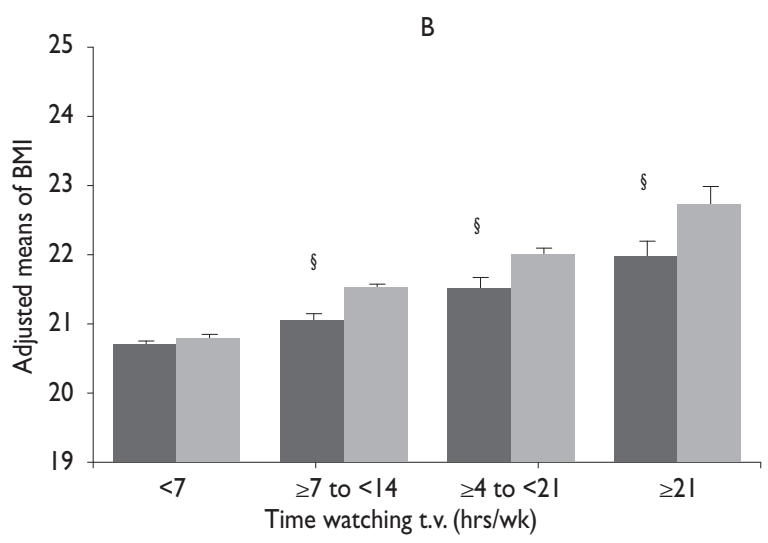

High intake

A. Adjusted means by diet drinks, non beverage energy, age, socioeconomic characteristics (SES and area), time watching TV and the interaction between SSBs and age in a lineal regression model ( $p$ value's interaction $=0.02$ )

B. Adjusted means by diet drinks, non beverage energy, age, socioeconomic characteristics (SES and area), time watching TV and the interaction between SSBs and time watching TV in a lineal regression model ( $p$ value's interaction $=0.15$ )

* Low intake: 10 to $12 y=0.00,0.83$ serv $/ d$; 13 to $15 y=0.00,0.02$ serv $/$ d; 16 to $19 y=0.00,1.24$ serv $/ \mathrm{d}$

¥ High intake: 10 to $12 y=0.86,8.57$ serv/d; 13 to $15 y=1.03,12.00$ serv $/ \mathrm{d}$; 16 to $19 y=1.29$, 11.30 serv $/ \mathrm{d}$

$\S$ Significant difference between low and high intake of SSBs ( $p<0.05$ adjusted in a lineal regression model)

Figure I. Adjusted means of BMI in males adolescents, by sugar-sWeetened beVerages tYPe and age and time WATChing TV. Mexico, ENSANUT 2006

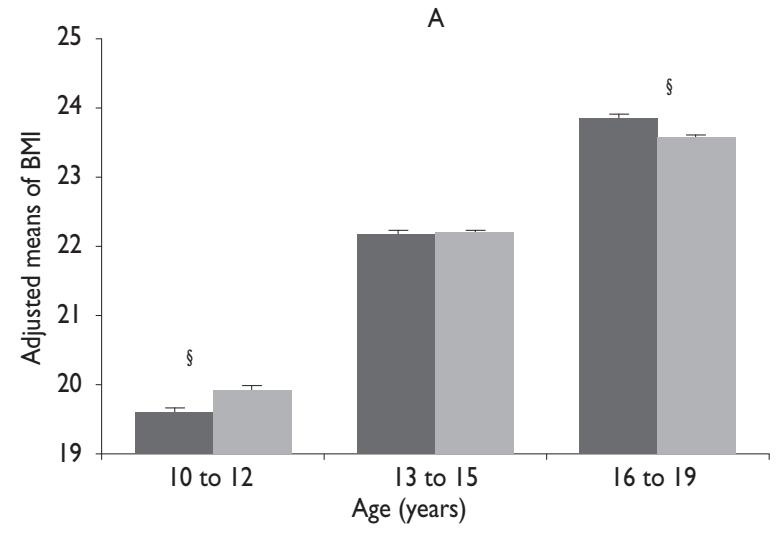

Servings per day: Low intake*

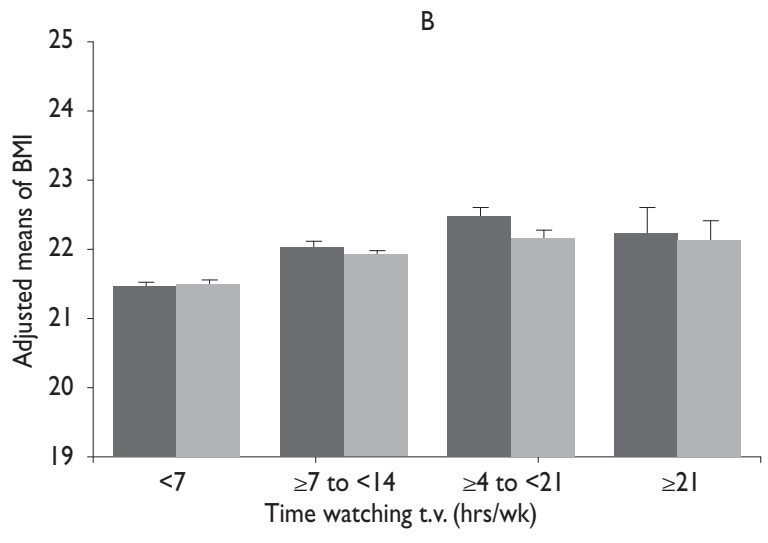

High intake

A. Adjusted means by diet drinks, non beverage energy, age, socioeconomic characteristics (SES and area), time watching TV, menarche and the interaction between SSBs and age in a lineal regression model ( $p$ value's interaction $=0.07$ )

B. Adjusted means by diet drinks, non beverage energy, age, socioeconomic characteristics (SES and area), time watching TV, menstruation, and the interaction between SSBs and time watching TV in a lineal regression model ( $p$ value's interaction $=0.89)$

* Low intake: 10 to $12 y=0.00,0.85$ serv $/ d ; 13$ to $15 y=0.00,1.00$ serv $/ d$; 16 to $19 y=0.00,0.92 \mathrm{serv} / \mathrm{d}$

\# High intake: 10 to $12 y=0.86,7.50$ serv $/ \mathrm{d}$; 13 to $15 y=1.01,11.35$ serv $/ \mathrm{d}$; 16 to $19 y=0.93$, $10.7 \mid \mathrm{serv} / \mathrm{d}$

$\S$ Significant difference between low and high intake of SSBs ( $p<0.05$ adjusted in a lineal regression model)

Figure 2. Adjusted means of BMI in females Adolescents, for sugar-sWeetened beVerages type, AGe and time WATCHING TV. MeXICO, ENSANUT 2006 
In panel $B$, it is observed that in the category of 7 hrs of TV per week, there were no significant differences between male adolescents with a lower consumption of SSBs compared to males with a higher consumption of SSBs $(p>0.05)$, while in the categories of more than $7 \mathrm{hrs}$ of TV per week it was observed that males with a greater consumption of SSBs had a higher BMI compared to those with a lower consumption of SSBs $(p<$ 0.05) (Figure 1).

Figure 2 presents the adjusted mean BMI for girls resulting from the regression models that included interaction terms between the consumption of SSBs and age, and between the consumption of SSBs and TV-viewing time. In panel A, it is observed for the group of female adolescents 10 to 12 years old that the BMI was higher in those who had a higher consumption of SSBs compared to those who had a lower consumption of SSBs $(p<0.05)$. The oldest females (16 to 19 years) who had a higher intake had a BMI lower than those who had a lower consumption of SSBs ( $p<0.05)$. In panel B, it is observed in the categories of more than $7 \mathrm{hrs}$ of TV per week that the females who had a greater consumption of SSBs had a lower BMI with respect to those who had a lower consumption of SSBs, but the differences were not significant $(p>0.05)$ (Figure 2).

Through a regression model that included the interaction term between consumption of SSBs and the presence of menarche (interaction term: $\beta=-0.24,95 \%$ CI: $-0.46-0.01, p=0.04)$ it was noted that female adolescents who had already presented menarche and had a higher consumption of SSBs had a lower BMI (22.7, SE= 0.03 ) with respect to those who had a lower intake of SSBs $(22.9, S E=0.03)(p<0.05)$. Female adolescents who had not yet presented menarche and who had a higher consumption of SSBs had a higher BMI $(19.3, S E=0.04)$ than those who had a lower intake of SSBs (19.1, SE= $0.03)(p<0.05)$ (data not shown).

\section{Discussion}

We analyzed the relationship between consumption of sugar-sweetened beverages (SSBs) and BMI in a sample of adolescents who participated in a nationally representative Mexican survey (ENSANUT 2006).

The results showed that consumption of sodas were positively associated with BMI for male adolescents, after adjusting for potential confounders. Moreover, positive interactions of SSB consumption with age and TV-viewing time were observed in males. Giammattei $e t$ al. showed a similar interaction between SSB consumption with TV-viewing time, finding a significant positive association in adolescents between BMI with hours of television watched per evening and daily soft drink consumption $(p<0.05) .{ }^{17}$

Among female adolescents, no significant associations were found. This finding is consistent with previous studies, which have shown more consistent associations in males compared to females. However, the results are quite diverse. ${ }^{18,19}$

It is important to mention that the results in female adolescents with respect to age group show a different direction than expected; we observed that in the oldest group of females (16 to 19 years), those who had a higher intake had a lower BMI compared with those females who had a lower consumption of SSBs $(p<0.05)$. This situation could be due to reverse causation, since it is possible that the oldest group of females has a greater concern about body weight than the youngest group. Thus, female adolescents 16 to 19 years with a greater BMI tended to consume less SSBs than those 16 to 19 years who had a lower BMI.

In general terms, the prevalence of overweight and obesity, consumption of different types of beverages, as well as the effect of the consumption of SSBs on BMI found in our study coincide with other studies. For example, Berkey et al. found that for male adolescents who increased their soda intake by $\geq 2$ servings per day from the previous year gained weight ( 0.14 increase in BMI). ${ }^{19}$ Ludwig et al. found at baseline consumption of SSBs that in the fully adjusted model, BMI increased by 0.18 for each serving consumed per day (95\% CI: 0.09-0.27; $p=$ $0.02) .{ }^{8}$ Phillips et al. found that subjects in the third and fourth quartiles of percentage of calories from soda had $\mathrm{BMI}_{Z}$ scores of 0.17 units higher, on average, than those of subjects in the fist quartile $(p<0.001) .{ }^{20}$ In another study conducted among Mexican adolescents (10 to 19 years), the association between the consumption of SSBs and BMI was greater than that observed in this study. Denova et al. found that for each additional SSBs serving consumed daily, adolescents BMI increased by $0.33(p<0.001){ }^{21}$

The review by Malik ${ }^{5}$ has confirmed the notion about a positive association between consumption of SSBs and weight gain in different populations. The biological plausibility of how the consumption of SSBs can influence body weight is still unknown. It has been suggested that the consumption of energy through liquid food tends to generate a lower sense of satiety as compared to the intake of solid foods, resulting in a higher consumption of food in subsequent meals and, therefore, a larger total energy consumption. ${ }^{22}$ However, in our study we controlled for non-beverage energy intake and this did not affect the results. In one study among obese adolescents that compared satiety after 
consuming the same amount of energy through liquid foods versus solid foods, no difference in satiety was observed. ${ }^{23}$ Among other assumptions, it has been proposed that the sugars contained in the SSBs could prove addictive. A study in rats showed that after withdrawal of a sugar-rich diet, the animals showed qualitatively clear signs of dependence on sugars, similar to those presented in morphine and nicotine addiction, including teeth chattering and anxiety. ${ }^{24}$ On the other hand, it is possible that consumption of SSBs is only one component of a feeding pattern that favors body weight gain, or perhaps a reflection of an "obesogenic" lifestyle. A relationship was tested in an intervention study aimed to reduce the consumption of SSBs by American adolescents, and a significant reduction of body weight was observed among overweight and obese adolescents regardless of lifestyle variables. ${ }^{25}$

The interpretation of our results should consider certain limitations. The most important limitation deals with the cross-sectional nature of our study, which does not allow for making causal inferences between consumption of SSBs and increased BMI. However, our results coincide with previous longitudinal studies that suggest a cause-effect association (that is, consumption of SSBs precedes and has a positive association with weight gain). Thus, one could rule out the idea of a reverse causality for male adolescents (being overweight or obese promotes the intake of SSBs).

Another limitation is related to the use of a FFSQ, which was not specifically designed for accurately measuring beverage intake. Moreover, the portion size was standardized as $240 \mathrm{ml}$, and it could be that the children were consuming larger portion sizes. If this were the case, our study could be underestimating beverage consumption in this population. The overall result would be an overestimation of the actual effect associated with the consumption of one portion of SSBs.

Some of the strengths of the present study consist of the use of a large, nationally representative sample of Mexican adolescents, as well as the use of standardized personnel and methods. Additionally, the subjects and interviewers were blinded to the hypothesis of the study. Finally, we controlled in the multivariate analyses for potential confounders.

In conclusion, there was a positive association between the consumption of sodas and BMI in a nationally representative sample of Mexican adolescents. However this association was observed in males only. While it is necessary to conduct further studies on the subject with longitudinal design, it is also important to take immediate actions in this regard, such as encouraging the decrease in consumption of SSBs, as well as promoting the consumption of plain water for preventing and controlling the epidemic of overweight and obesity in Mexico. The Secretary of Health has recently undertaken an effort in this regard when designing the "recommendations for beverages' consumption for a healthy lifestyle for the mexican population".

\section{Acknowledgments}

We would like to acknowledge Dr. Bernardo Hernández for his advice in writing the manuscript and Alfonso Mendoza for database management.

\section{References}

I. Rivera J, Barquera S, Campirano F, Campos I, Safdie M, TovarV. Epidemiological and nutritional transition in Mexico: rapid increase of non-communicable chronic diseases and obesity. Public Health Nutrition 2002;5: II3-122.

2. Fernández O, Rivera J, Shamah T,Villalpando S, Hernández M, Sepúlveda J. Encuesta Nacional de Salud y Nutrición 2006. Cuernavaca, Mexico: Instituto Nacional de Salud Pública, 2006.

3. Gómez A. Cada año, I52 litros de refresco por mexicano. La prensa. Organización Editorial Mexicana. 2008 June. [Consulted 2008 November 2 Ist.].Available at: http://www.oem.com.mx/laprensa/notas/n752335.htm. 4. Rivera JA, Muñoz O, Rosas M, Aguilar CA, Popkin BM, Willett WC. Consumo de bebidas para una vida saludable: recomendaciones para la población mexicana. Salud Publica Mex 2008; 50:173-195.

5. MalikVS, Schulze MB, Hu FB. Intake of sugar-sweetened beverages and weight gain: a systematic review.Am J Clin Nutr 2006;84:274-288.

6. Ramírez I, Mundo V, Rodríguez S, Vizuet I, Hernández N, Jiménez A. Encuestas dietéticas. In: Manual de procedimientos para proyectos de nutrición. Cuernavaca, Mexico: Instituto Nacional de Salud Pública, 2006; 27-108.

7. Ludwig DS, Peterson KE, Gortmaaker S. Relation between consumption of sugar-sweetened drinks and childhood obesity: a prospective, observational analysis. Lancet 200I;357:505-508.

8. Lohman TG, Roche AF, Martorell R. Anthropometric standardization reference manual. Champaign (IL): Human Kinetics Books, 1998.

9. Habicht JP. Standarization of anthopometric methods in the field. PAHO Bull 1974;76:375-384.

10. Cole T J, Bellizzi MC, Flegal KM, Dietz WH. Establishing a Standard definition for child overweight and obesity worldwide: international survey. BMJ 2000;320:1240.

II. Must A, Dallal G, Dietz W. Reference data for obesity: 85th and 95th percentiles of body mass index ( $w t / h t 2)$ and triceps skin fold thickness. Am J Clin Nutr 1991;53:839-846.

12. Reyment R, Jöreskog K. Applied factor analysis in the natural sciences. Cambridge, UK: Cambridge University Press, 1996: 371.

13. Hair JF,Anderson R, Tatham R, BlackW. Multivariate data analysis with readings. 3rd ed. New York (NY): Macmillan Publishing Company, 1992: 223-253.

14. Hernández B, Gortmaker S, Laird N, Colditz G, Parra-Cabrera S, Peterson K.Validez y reproducibilidad de un cuestionario de actividad e inactividad física para escolares de la ciudad de México. Salud Publica Mex 2000;42:315-323.

15. American Academy of Pediatrics. Committee on Public Education Pediatrics. Pediatrics 200I; 108:1222-I 225.

16. World Health Organization. El estado físico: uso e interpretación de la antropometría. Informe de un Comité de Expertos de la OMS. Geneva: WHO, 1995. 
17 Giammattei J, Blix G, Marshak HH,Wollitzer AO, Pettitt DJ.Television watching and soft drink consumption: associations with obesity in II- to 13- year-old schoolchildren. Arch Pediatr Adolesc Med 2003;157:882-886. 18. Gillis LJ, Bar-Or O. Food away from home, sugar-sweetened drink consumption and juvenile obesity. J Am Coll Nutr 2003;22:539-545. 19. Berkey CS, Rockett HR, Field AE, Gillman MW, Coditz GA. Sugar added beverage and adolescent weight change. Obes Res 2004;12:778-788. 20. Phillips SM, Bandini LG, Naumova EN, Cyr H, Colclough S, Dietz $\mathrm{WH}$, et al. Energy-dense snack food intake in adolescents: longitudinal relationship to weight and fatness. Obes Res 2004; 12:461-472.

21. Denova E, Jiménez A, Halley E, Huitrón G, Talavera JO, Pineda D, et al. Association between Sweetened Beverage Consumption and Body Mass Index, Proportion of Body Fat and Body Fat Distribution in Mexican Adolescents. Ann Nutr Metab 2008;53:245-25I.
22. Mattes RD. Dietary compensation by humans for supplemental energy provided as ethanol or carbohydrate in fluids. Physiol Behav 1996;59:179-187. 23. Almiron E, Flores SY, Drewnowski A. No difference in satiety or in subsequent energy intakes between a beverage and a solid food. Physiol Behav 2004;82:67I-677.

24. Colantuoni C, Rada P, McCarthy J, Petten C,Avena NM, Chadeayne A, et al. Evidence that intermittent, excessive sugar intake cause endogenous opiate dependence. Obes Res 2002; 10:478-488.

25. Ebbeling CB, Feldman HA, Osganian SK, Chomitz VR, Ellenbogen SJ, Ludwig DS. Effects of decreasing sugar-sweetened beverage consumption on body weight in adolescents: a randomized, controlled pilot study. Pediatrics 2006; I 17:673-680 